\title{
Cosmetic Professionals' Awareness of Body Dysmorphic Disorder
}

Citation for published version (APA):

Bouman, T. K., Mulkens, S., \& van der Lei, B. (2017). Cosmetic Professionals' Awareness of Body Dysmorphic Disorder. Plastic and Reconstructive Surgery, 139(2), 336-342.

https://doi.org/10.1097/PRS.0000000000002962

Document status and date:

Published: 01/02/2017

DOI:

10.1097/PRS.0000000000002962

Document Version:

Publisher's PDF, also known as Version of record

Document license:

Taverne

Please check the document version of this publication:

- A submitted manuscript is the version of the article upon submission and before peer-review. There can be important differences between the submitted version and the official published version of record.

People interested in the research are advised to contact the author for the final version of the publication, or visit the DOI to the publisher's website.

- The final author version and the galley proof are versions of the publication after peer review.

- The final published version features the final layout of the paper including the volume, issue and page numbers.

Link to publication

\footnotetext{
General rights rights.

- You may freely distribute the URL identifying the publication in the public portal. please follow below link for the End User Agreement:

www.umlib.nl/taverne-license

Take down policy

If you believe that this document breaches copyright please contact us at:

repository@maastrichtuniversity.nl

providing details and we will investigate your claim.
}

Copyright and moral rights for the publications made accessible in the public portal are retained by the authors and/or other copyright owners and it is a condition of accessing publications that users recognise and abide by the legal requirements associated with these

- Users may download and print one copy of any publication from the public portal for the purpose of private study or research.

- You may not further distribute the material or use it for any profit-making activity or commercial gain

If the publication is distributed under the terms of Article $25 \mathrm{fa}$ of the Dutch Copyright Act, indicated by the "Taverne" license above, 


\title{
Cosmetic Professionals' Awareness of Body Dysmorphic Disorder
}

\author{
Theo K. Bouman, Ph.D. \\ Sandra Mulkens, Ph.D. \\ Berend van der Lei, M.D., \\ Ph.D. \\ Groningen and Maastricht, \\ The Netherlands
}

\section{$\mathbf{P}$} reoccupation with a perceived appearance flaw that leads to personal, social, and occupational impairment is the main feature of body dysmorphic disorder. ${ }^{1}$ Some refer to this condition as distorted body image or extreme body dissatisfaction. Depression is prevalent and suicide risk is high among patients suffering from body dysmorphic disorder, with approximately 80 percent of them having suicidal ideation, even leading to one or more suicide attempts in 25 percent of the cases. ${ }^{2}$ Patients suffering from body dysmorphic disorder engage in various behaviors to

From the Department of Clinical Psychology, University of Groningen; the Department of Clinical Psychological Science, Maastricht University; the Department of Plastic Surgery, University of Groningen and University Medical Centre Groningen.

Received for publication March 14, 2016; accepted September 14, 2016.

Copyright $@ 2017$ by the American Society of Plastic Surgeons

DOI: 10.1097/PRS.0000000000002962 (unsuccessfully) decrease the distress caused by their extreme body dissatisfaction. Frequent mirror gazing, camouflaging, extensive grooming, and avoiding social situations are only a few of these. The majority of patients with body dysmorphic disorder seek and often undergo some type of dermatologic, surgical, or minimally invasive procedure. ${ }^{3}$ However, satisfaction with cosmetic procedures is generally low, and often leads to the desire to undergo even more procedures. ${ }^{3}$ Because body dysmorphic disorder is essentially a body image problem, it is perceived as a contraindication for cosmetic procedures, yielding no improvement or even worsening in as many as 95 percent of patients diagnosed with body dysmorphic disorder. ${ }^{4}$

Disclosure: The authors have no financial interest to declare in relation to the content of this article. This work was not supported by outside funding. 
The prevalence of body dysmorphic disorder is approximately 2 percent in the general population. ${ }^{1,5,6}$ In cosmetic settings, this number is far higher and estimated to be approximately 10 percent, ranging from 5 to 15 percent. ${ }^{7}$ Some of the larger specific studies found, for instance, rates of 9.1 percent in 132 cosmetic surgical patients, ${ }^{8} 31.1$ percent in 234 cosmetic facial surgery patients, ${ }^{9}$ 9.5 percent in 170 cosmetic orthodontic patients, ${ }^{10}$ and 11.6 percent in 268 dermatology patients. ${ }^{11}$ Given that body dysmorphic disorder is a contraindication implies that cosmetic professionals should be aware of this condition and should act accordingly. However, a complication is the body dysmorphic disorder patients' strong tendency to conceal the nature of their desire to undergo any type of cosmetic procedure.

In the literature, we found only three studies addressing cosmetic professionals' knowledge of body dysmorphic disorder and their approach to patients diagnosed as such: two studies carried out in the United States ${ }^{12,13}$ and one in Poland, ${ }^{14}$ all among a single cosmetic discipline, pertaining to either plastic surgeons or dermatologists. For that reason, the present study was undertaken to add to this limited body of knowledge by investigating both cosmetic professionals' awareness of body dysmorphic disorder and the way they act on this awareness, and to compare this among various cosmetic disciplines in The Netherlands.

\section{PARTICIPANTS AND METHODS}

\section{Participants}

All current members of three Dutch professional associations for aesthetic plastic surgery (392 members), dermatology (480 members), and cosmetic medicine (131 members) were approached by means of their associations' digital mailing lists. An e-mail contained a link to an online survey that was available during July and August of 2015. A total of 216 of them started the survey, and 173 completed it, indicating a response rate of 17.2 percent. This procedure yielded four groups-plastic surgeons $(n=62)$, dermatologists $(n=57)$, cosmetic doctors (i.e., physicians who have not specialized in plastic surgery, but who are performing mainly cosmetic procedures such as filler injections and botulin toxin treatments) $(n=33)$, and other disciplines $(n=21)$, mainly maxillofacial surgeons $(n=9)$ and various residents $(n=7)$. This latter group consists of members of the aforementioned association that did not belong to one of the core disciplines.
Characteristics of the survey participants are listed in Table 1. No significant differences were found between disciplines regarding age and years of experience. However, the total sample consisted of significantly more male plastic surgeons and more female dermatologists (chisquare $=15.8 ; d f=3 ; p<0.001)$. Furthermore, groups differed significantly in the number of new patients they saw per year (chi-square $=15.8$; $d f=3 ; p<0.001)$, with more dermatologists seeing over 500 new patients, and more cosmetic doctors seeing between 350 and 500 new patients.

\section{Instrument}

An Internet survey using Qualtrics (Qualtrics, LLC, Provo, Utah) consisting of 33 multiplechoice questions was designed for the purpose of this study. The survey investigated participants' knowledge about body dysmorphic disorder and their opinions on the way they are (or would be) dealing with this condition. The questions and their response categories are presented in Tables 1 through 4. After inquiring for personal data, the full Diagnostic and Statistical Manual of Mental Disorders (5th ed.) ${ }^{1}$ criteria for body dysmorphic disorder were presented on a separate screen, and question were asked to explore participants' familiarity with these criteria (Table 2). Subsequent questions focused on the way participants dealt with patients whom they suspected of suffering

Table 1. Characteristics of Participants

\begin{tabular}{|c|c|}
\hline Characteristic & Value $(\%)$ \\
\hline \multicolumn{2}{|l|}{ Sex } \\
\hline Female & $80(46.2)$ \\
\hline Male & $93(53.8)$ \\
\hline \multicolumn{2}{|l|}{ Specialty } \\
\hline Plastic surgeon & $62(35.8)$ \\
\hline Dermatologist & $57(32.9)$ \\
\hline Cosmetic doctor & $33(19.1)$ \\
\hline Other & $21(12.1)$ \\
\hline \multicolumn{2}{|l|}{ Employment setting* } \\
\hline Private clinic & $74(42.7)$ \\
\hline Self-employed & $44(25.4)$ \\
\hline University hospital & $37(21.4)$ \\
\hline General hospital & $96(55.5)$ \\
\hline \multicolumn{2}{|c|}{ No. of new patients per year } \\
\hline$<200$ & $10(5.8)$ \\
\hline$>200-350$ & $23(13.3)$ \\
\hline$>350-500$ & $26(15.0)$ \\
\hline$>500$ & $114(65.9)$ \\
\hline \multicolumn{2}{|l|}{ Age, vr } \\
\hline Mean \pm SD & $44.4 \pm 9.5$ \\
\hline Range & $26-67$ \\
\hline \multicolumn{2}{|l|}{ Years of employment } \\
\hline Mean \pm SD & $10.4 \pm 8.3$ \\
\hline Range & $1-36$ \\
\hline
\end{tabular}
one institution. Percentages of employment are relative to $n=173$. 
Plastic and Reconstructive Surgery • February 2017

Table 2. Response Frequency and Group Differences Regarding Familiarity with Body Dysmorphic Disorder

\begin{tabular}{|c|c|c|c|c|}
\hline & No. $(\%)$ & $\chi^{2}$ & $d f$ & $p$ \\
\hline 1. Are you familiar with the diagnostic criteria for BDD? & & 15.6 & 9 & 0.075 \\
\hline a. I'm seeing these criteria now for the first time & $10(5.8)$ & & & \\
\hline b. I've heard of these & $24(13.9)$ & & & \\
\hline c. I'm slightly familiar with these & $51(29.5)$ & & & \\
\hline d. I have been familiar with these for a long time & $88(50.9)$ & & & \\
\hline 2. Are you familiar with the clinical picture of BDD? & & 11.5 & 9 & 0.245 \\
\hline a. I'm not familiar with this & $1(0.6)$ & & & \\
\hline b. I'm partly familiar with this & $64(37.0)$ & & & \\
\hline c. I'm reasonably familiar with this & $73(42.2)$ & & & \\
\hline d. I'm totally familiar with this & $35(20.2)$ & & & \\
\hline \multicolumn{5}{|l|}{ 3. How did you acquire knowledge on BDD?* } \\
\hline a. No knowledge & $3(1.7)$ & 0.7 & 3 & 0.873 \\
\hline b. General professional literature & $102(59.0)$ & 1.0 & 3 & 0.802 \\
\hline c. Specific literature on BDD & $49(28.3)$ & 4.4 & 3 & 0.219 \\
\hline d. Conferences or lectures & $115(66.5)$ & 2.0 & 3 & 0.572 \\
\hline e. Colleagues & $79(45.7)$ & 3.5 & 3 & 0.313 \\
\hline f. Web sites & $21(12.1)$ & 6.9 & 3 & 0.074 \\
\hline \multicolumn{2}{|l|}{ 4. How do you estimate the prevalence of BDD in cosmetic practice? } & 24.2 & 9 & 0.004 \\
\hline a. Approximately 5\% & $63(36.4)$ & & & \\
\hline b. Approximately $10 \%$ & $50(28.9)$ & & & \\
\hline c. Approximately $15 \%$ & $33(19.1)$ & & & \\
\hline d. I have no idea & $27(15.6)$ & & & \\
\hline \multicolumn{2}{|l|}{ 5. Did you encounter patients with BDD over the past year? } & 3.4 & 9 & .948 \\
\hline a. No, I didn't encounter any & $16(9.2)$ & & & \\
\hline b. Yes, by hindsight I've probably encountered them & $26(15.0)$ & & & \\
\hline c. Yes, by hindsight I've certainly encountered them & $23(13.3)$ & & & \\
\hline d. Yes, I've certainly encountered them & $108(62.4)$ & & & \\
\hline \multicolumn{2}{|l|}{ 6. How many patients with BDD did you see last year? } & 4.5 & 9 & .873 \\
\hline a. None & $16(9.2)$ & & & \\
\hline b. $1-5$ patients & $104(60.1)$ & & & \\
\hline c. $5-10$ patients & $40(23.1)$ & & & \\
\hline d. $>11$ patients & $13(7.5)$ & & & \\
\hline
\end{tabular}

BDD, body dysmorphic disorder.

* More than one answer could be given. Each of these percentages relate to $n=173 ; \chi^{2}$ tests have been carried out for each separate answer.

from body dysmorphic disorder (Table 3), and their opinions about body dysmorphic disorder and its impact on cosmetic procedures (Table 4).

\section{RESULTS}

This section presents results for the entire sample and potential differences between the professional groups. First, several questions gauged participants' familiarity with the diagnosis of body dysmorphic disorder. As is shown in Table 2, most professionals indicated being more or less familiar with the diagnostic criteria and the clinical picture of body dysmorphic disorder. By far the most important sources of information were conferences and lectures, and general professional literature. Approximately two-thirds of the participants encountered between one and five of these patients in their practice over the past year. The groups only differed significantly on their estimate of body dysmorphic disorder prevalence $($ chi-square $=24.2 ; d f=9 ; p<0.004)$, with more dermatologists endorsing the 15 percent answer and more cosmetic doctors endorsing the 5 percent answer.
Table 3 summarizes the ways in which participants reported dealing with body dysmorphic disorder patients. The majority of cosmetic professionals "sometimes" or "often" address body image problems during consultation. For only a minority (6.9 percent), however, this is a standard procedure. Slightly less than half of them collaborate with psychologists or psychiatrists, and approximately 70 percent refuse to perform a procedure in a patient they suspect suffering from body dysmorphic disorder. In addition (not reported in a table), approximately 90 percent of participants would consider using a screening instrument for body dysmorphic disorder (15 percent as a standard procedure), and providing their patients with an information brochure (17 percent as a standard procedure).

As can be seen in Table 3, chi-square tests showed that the four groups of cosmetic professionals differed on five of six questions. Post hoc analyses using standardized residuals were used to detect which of the groups differed significantly from the others. The dermatologists were significantly more likely to never discuss disturbed body 
Table 3. Frequencies and Group Differences in Dealing with Body Dysmorphic Disorder and Disturbed Body Image

\begin{tabular}{|c|c|c|c|c|}
\hline & No. $(\%)$ & $\chi^{2}$ & $d f$ & $p$ \\
\hline 1. Do you explore BDD or disturbed body image during the intake interview? & & 19.1 & 9 & 0.024 \\
\hline a. Never. & $30(17.3)$ & & & \\
\hline b. Sometimes & $99(57.2)$ & & & \\
\hline c. Often & $32(18.5)$ & & & \\
\hline d. Always & $12(6.9)$ & & & \\
\hline 2. In patients with BDD, do you shift the topic from the technical aspects of the procedure & & & & \\
\hline to body image problems? & & 12.7 & 9 & 0.177 \\
\hline a. No. Body image is never part of the intake interview & $8(4.6)$ & & & \\
\hline b. Sometimes & $63(36.4)$ & & & \\
\hline c. Most of the time & $55(31.8)$ & & & \\
\hline d. Always, because body image is a standard topic during the intake interview & $47(27.2)$ & & & \\
\hline 3. In case of BDD or disturbed body image, do you share this with your patient? & & 24.8 & 9 & 0.003 \\
\hline a. No, I keep that to myself & $12(6.9)$ & & & \\
\hline b. Sometimes & $62(35.8)$ & & & \\
\hline c. Most of the time & $58(33.5)$ & & & \\
\hline d. Yes, always & $41(23.7)$ & & & \\
\hline 4. What do you do when you recognize or suspect BDD in a patient? & & 33.8 & 21 & 0.038 \\
\hline a. I don't address this & $2(1.2)$ & & & \\
\hline b. I approach such a patient no different from other patients & $8(4.6)$ & & & \\
\hline c. I share my impression on this patient's appearance & $37(21.4)$ & & & \\
\hline d. I talk about the patient's disturbed body image & $54(31.2)$ & & & \\
\hline e. First, I consult a psychologist about what & $7(4.0)$ & & & \\
\hline f. I refer the patient to a psychiatrist or a psychologist and decline the procedure & $25(14.5)$ & & & \\
\hline $\begin{array}{l}\text { g. First, I refer the patient to a psychiatrist or a psychologist, and possibly carry out the } \\
\text { requested procedure later }\end{array}$ & & & & \\
\hline h. I carry out the procedure in parallel with psychological care & $\begin{aligned} 39 & (22.5 \\
1 & (0.6)\end{aligned}$ & & & \\
\hline 5. Have you ever refused treating a patient with (the suspicion of) BDD? & & 21.1 & 9 & 0.017 \\
\hline a. I've never dealt with this & $12(6.9)$ & & & \\
\hline b. I would do so, if this would happen & $37(21.4)$ & & & \\
\hline c. I have done so in a number of patients & $95(54.9)$ & & & \\
\hline $\mathrm{d}$. This is what I always do & $29(16.8)$ & & & \\
\hline 6. Have you ever been threatened by a patient with BDD? & & 13.6 & 6 & 0.035 \\
\hline a. No, this has never happened to me & $134(77.5)$ & & & \\
\hline b. I have been physically threatened & $0(0.0)$ & & & \\
\hline c. I have been verbally threatened & $28(16.2)$ & & & \\
\hline d. I have been threatened with legal steps & $11(6.4)$ & & & \\
\hline
\end{tabular}

BDD, body dysmorphic disorder.

Table 4. Opinions about Cosmetic Surgery

\begin{tabular}{|c|c|c|c|c|c|c|c|}
\hline & \multicolumn{5}{|c|}{ Response Categories* } & \multirow[b]{2}{*}{ Mean } & \multirow[b]{2}{*}{ SD } \\
\hline & 1 & 2 & 3 & 4 & 5 & & \\
\hline $\begin{array}{l}\text { 1. I usually get a gut feeling that something is wrong when seeing patients } \\
\text { with BDD }\end{array}$ & 1.7 & 1.7 & 10.4 & 67.1 & 19.1 & 4.0 & 0.7 \\
\hline 2. I find it challenging to deal with patients with $\mathrm{BDD} \dagger$ & 4.0 & 18.5 & 26.0 & 48.6 & 2.9 & 3.3 & 0.9 \\
\hline 3. I find BDD a contraindication for an aesthetic procedure $\dagger$ & 0.6 & 8.1 & 20.8 & 45.7 & 24.9 & 3.9 & 0.9 \\
\hline $\begin{array}{l}\text { 4. Patients with BDD have realistic expectations on the impact of the aesthetic } \\
\text { procedure on their daily functioning }\end{array}$ & 43.9 & 51.4 & 4.0 & 0.0 & 0.6 & 1.6 & 0.6 \\
\hline $\begin{array}{l}\text { 5. Patients with BDD have realistic expectations on the physical results of the } \\
\text { aesthetic procedure }\end{array}$ & 30.6 & 58.4 & 7.5 & 2.9 & 0.6 & 1.8 & 0.7 \\
\hline $\begin{array}{l}\text { 6. Patients with BDD benefit equally from aesthetic procedures as other } \\
\text { patients }\end{array}$ & 23.1 & 57.8 & 17.3 & 1.7 & 0.0 & 2.0 & 0.7 \\
\hline 7. If a patient wants an aesthetic procedure, I will always carry this out & 52.6 & 39.9 & 5.2 & 0.0 & 2.3 & 1.6 & 0.8 \\
\hline 8. If I think an aesthetic procedure to be unnecessa & 1.7 & 0.6 & 7.5 & 50.3 & 39.9 & 4.3 & 0.8 \\
\hline 9. Even if I find an aesthetic procedure unnecessary, I'll still care this out & 31.8 & 39.3 & 22.5 & 5.8 & 0.6 & 2.0 & 0.9 \\
\hline $\begin{array}{l}\text { 10. If I find an aesthetic procedure unnecessary, I refer the patient to a col- } \\
\text { league }\end{array}$ & 14.5 & 42.8 & 27.7 & 12.1 & 2.9 & 2.5 & 1.0 \\
\hline 11. Aesthetic procedures are a luxury article, but also patient care* & 1.7 & 7.5 & 15.0 & 56.6 & 19.1 & 3.8 & 0.9 \\
\hline 12. Aesthetic procedures are basically a kind of "psychotherapy/psychosurgery" & 16.2 & 38.7 & 30.1 & 12.7 & 2.3 & 2.5 & 1.0 \\
\hline
\end{tabular}

BDD, body dysmorphic disorder.

$* 1=$ don't agree at all; $3=$ neutral; and $5=$ totally agree.

$\dagger$ Significant differences between professional groups. 
image, whereas more cosmetic doctors reported always doing so (question 1). Plastic surgeons were significantly more inclined than the other samples to always share their suspicion of body dysmorphic disorder with their patients, and more dermatologists said they did so "sometimes" (question 3). Significantly more plastic surgeons indicated first referring a patient suspected of body dysmorphic disorder to a psychiatrist or a psychologist before considering a cosmetic procedure (question 4), and refusing treatment in a patient with body dysmorphic disorder (question 5). Cosmetic doctors reported significantly more legal threats by patients compared with the other three groups (question 6).

The responses to 12 statements pertaining to cosmetic procedures for body dysmorphic disorder patients are presented in Table 4. Overall highest mean scores were found for the statements related to having a "gut feeling" that something is wrong (statement 1), considering body dysmorphic disorder to be a contraindication (statement 3), and telling the patient that a procedure is unnecessary (statement 8). Lowest mean scores were observed in statements that referred to the patient having realistic expectations, and going along with a patient's desire to have a procedure carried out.

On four of the statements (i.e., 2, 3, 8, and 12), analyses of variance revealed significant differences between groups. Post hoc analyses showed the following pattern. Plastic surgeons showed significant lower mean levels of agreement with the statement "I find it challenging to deal with patients with body dysmorphic disorder" $\left[F_{169,3}=14.4 ; p<0.003\right]$ and higher mean levels of agreement with the statement "Aesthetic procedures are basically a kind of psychotherapy/ psychosurgery" $\left[F_{169,3}=9.8 ; p<0.016\right]$ compared with the three other groups. Cosmetic doctors showed a significantly higher mean endorsement of the statement "If I think an aesthetic procedure to be unnecessary, I'll tell the patient" $\left[F_{169.3}=6.3\right.$; $p<0.012]$. Finally, the group called "other disciplines" had a significantly lower agreement with the statement "I find body dysmorphic disorder a contraindication for an aesthetic procedure" $\left[F_{169,3}=11.1 ; p<0.003\right]$. Finally, familiarity with body dysmorphic disorder criteria correlated significantly but low with years of experience $(r=0.22 ; p<0.003)$, and with the "gut feeling that something might be wrong" $(r=0.18 ; p<0.016)$.

\section{DISCUSSION}

The main finding of this study is that the cosmetic professionals had some degree of awareness of body dysmorphic disorder and that this guided their decision of whether or not to perform a procedure. Most of the professionals take their time to address body image problems and incorporate psychological consultation or care in their approach. These general results converge with those by Sarwer, ${ }^{12}$ Sarwer et al., ${ }^{13}$ and Szepietowski et al. ${ }^{14}$ Sarwer ${ }^{12}$ reported a survey of 265 members of the American Society for Aesthetic Plastic Surgery. Their results indicated that the vast majority of respondents were aware of body dysmorphic disorder and that this was taken into consideration when deciding to operate or not. However, only 30 percent considered body dysmorphic disorder a contraindication for surgery. Szepietowski al. ${ }^{14}$ found in their survey among 118 dermatologists in Poland that 45 percent of them had encountered at least one patient suffering from body dysmorphic disorder in the past 5 years. Approximately 70 percent of them had always or often asked for a psychiatric opinion about their patients. In a survey among 260 dermatologic surgeons in the United States, Sarwer et al. ${ }^{13}$ investigated participants' strategies for identification and management of mental health issues among patients seeking cosmetic procedures. Almost all of the dermatologists were aware of body dysmorphic disorder and approximately two-thirds considered this to be a contraindication for a procedure and subsequently refused to treat body dysmorphic disorder patients.

Despite much similarity of our general findings with the three aforementioned studies, ${ }^{12-14}$ some of our results merit further discussion. Although the majority of the professionals in our study reported encountering body dysmorphic disorder patients in their practice, these numbers are at variance with prevalence data. Seeing over 500 candidate cosmetic patients per year, 83.2 percent of the professionals recognized between one and 10 body dysmorphic disorder patients, which is lower (i.e., maximum 2 percent) than would be expected given the 10 percent prevalence of body dysmorphic disorder in these settings. The findings of Sarwer ${ }^{12}$ and Szepietowski et al. ${ }^{14}$ carry a similar impression that might be interpreted as underdiagnosis. The dermatologists in the study by Sarwer et al., ${ }^{13}$ however, identified approximately 13 percent of body dysmorphic disorder patients in their practice, a significantly higher percentage probably lying close to reality. It might be the case that these dermatologists are well trained to recognize body dysmorphic disorder. In addition, the participants' estimates of the prevalence of body dysmorphic disorder vary, with only 
a minority of them endorsing the correct answer of approximately 10 percent.

A somewhat paradoxical finding is that only a minority of the professionals admitted exploring body image (problems) with every prospective patient (question 1 in Table 3). However, in response to another question, approximately half of them reported discussing these topics "always" or "most of the time" (question 3 in Table 3). This is quite remarkable, because the prime motive for undergoing a cosmetic procedure is some degree of body dissatisfaction. Therefore, one would expect these professionals to consider body image to be a standard element of an intake interview.

In contrast to Sarwer, ${ }^{12}$ who reported that only 30 percent of the plastic surgeons find body dysmorphic disorder a contraindication, our sample showed that over twice as many (i.e., 70.6 percent) (totally) agreed with this, which is approximately the same as the 63 percent found by Sarwer et al. ${ }^{13}$ in their survey among dermatologists. Most of our participants (70 percent) (answers $\mathrm{c}$ and $\mathrm{d}$ in Table 3 and question 9 in Table 4) would not carry out a procedure if they have the suspicion of body dysmorphic disorder. Similar to the findings by Szepietowski et al. ${ }^{14}$ and Sarwer et al. ${ }^{13}$ the majority of our participants indicated that they consulted a psychologist or a psychiatrist, pointing to the fact that these patients indeed are considered to require multidisciplinary care.

The interaction between cosmetic professionals and body dysmorphic disorder patients can get out of hand: a minority (16.2 percent) of our participants reported having been threatened verbally by body dysmorphic disorder patients, none physically, and 6.4 percent legally. These figures are lower than those reported by Sarwer ${ }^{12}$ (33 percent legally, 10 percent legally and physically, and 2 percent physically) and Sarwer et al. ${ }^{13}$ (9 percent legally and 2 percent physically). Cultural factors and communication styles with body dysmorphic disorder patients might explain these differences.

When comparing the four groups of professionals, plastic surgeons found it significantly less challenging to deal with body dysmorphic disorder patients, were more inclined to share their opinions about a disturbed body image, reported more often refusing a procedure in patients with body dysmorphic disorder, and more inclined to consider a cosmetic procedure as a form of psychotherapy. However interesting these differences are, replication studies should be carried out to establish the robustness of these findings. If that would be the case, the next question is how these differences can be explained. Plastic surgeons might for example be more inclined than the other disciplines to discuss and take body image problems into account because they perform invasive procedures with relatively permanent outcomes. The present descriptive study, however, does not allow for such premature speculations.

Although body dysmorphic disorder is considered a contraindication, it has been found by Veale et al. ${ }^{15}$ and by Felix et al. ${ }^{16}$ that, in patients with mild to moderate body dysmorphic disorder, rhinoplasty can lead to postoperative satisfaction. We would argue that this condition should not be an obstacle per se if patients are screened in advance to exclude those with severe body dysmorphic disorder and when the cosmetic procedure is embedded in psychological care. However, until now, we have only little and fragmentary insight about what is actually occurring between cosmetic professionals and patients suffering from body dysmorphic disorder at the outpatient clinic. Therefore, prospective studies are needed in which clinicians' behaviors are observed during their interaction with body dysmorphic disorder patients. In addition, a more detailed analysis of their clinical decision-making may inform us about the way in which they decide to perform a procedure. ${ }^{17}$ In an interesting study, Mirivel ${ }^{18}$ dissected the verbal and nonverbal communication during the initial assessment between plastic surgeons and their patients. In a subtle way, the surgeons incrementally constructed the patient's body as a territory of surgical need, thereby "selling" their cosmetic procedures. This methodology might also be of use for the opposite approach (i.e., talking at-risk patients out of procedures).

\section{Strengths and Limitations}

One of the strengths of this study is the comparison of various cosmetic professionals, in contrast to the three studies mentioned before. ${ }^{12-14} \mathrm{In}$ addition, our data from yet another country add to a broader insight into the ways in which cosmetic professionals are dealing with body dysmorphic disorder patients.

This study has a number of limitations that require cautious interpretation of the results. The total sample and the four subsamples were only limited in size. Participation in this Internet survey was on a voluntary basis, thereby introducing selfselection on the part of participants, obscuring the representativeness relative to the population of professionals. Data relied on self-report, rather than on observation of actual behaviors when dealing with patients, in particular those suffering 
from body dysmorphic disorder. Furthermore, the data are based on hindsight and therefore strongly rely on what participants remember about their patient encounters. Finally, social desirability may also be a factor that influences the responses, because no professional wants to appear ignorant.

\section{CONCLUSIONS}

Most of the cosmetic professionals in our sample reported having a considerable degree of awareness of body dysmorphic disorder and using this knowledge in their decision of whether or not to perform a cosmetic procedure. The apparent underdiagnosis of body dysmorphic disorder and its contraindication for cosmetic procedures leads us to the recommendation that it is important to inform cosmetic practitioners on the diagnosis and adequate treatment of body dysmorphic disorder, sometimes in a multidisciplinary context. Ideally, cosmetic professionals should be explicitly educated about recognizing and managing psychological contraindications (such as body dysmorphic disorder and body image problems) during their clinical training, just as they are informed about numerous somatic contraindications. This would make the exploration of body image problems (e.g., body dysmorphic disorder) a standard topic in every patient encounter in a cosmetic clinic.

Theo K. Bouman, Ph.D.

Department of Clinical Psychology University of Groningen Grote Kruisstraat 2 9712 TS Groningen, The Netherlands t.k.bouman@rug.nl

\section{ACKNOWLEDGMENTS}

The authors wish to thank Julia Herrmann for assistance in preparing the online survey. They are also greatly indebted to the professional associations and their members for their willingness to contribute to the survey.

\section{REFERENCES}

1. American Psychiatric Association. Diagnostic and Statistical Manual of Mental Disorders. 5th ed. Arlington, Va: American Psychiatric Association; 2013.
2. Phillips KA, Coles ME, Menard W, Yen S, Fay C, Weisberg RB. Suicidal ideation and suicide attempts in body dysmorphic disorder. J Clin Psychiatry 2005;66:717-725.

3. Phillips KA, Grant J, Siniscalchi J, Albertini RS. Surgical and nonpsychiatric medical treatment of patients with body dysmorphic disorder. Psychosomatics 2001;42:504-510.

4. Sarwer DB, Spitzer JC. Body image dysmorphic disorder in persons who undergo aesthetic medical treatments. Aesthet Surg J. 2012;32:999-1009.

5. Koran LM, Abujaoude E, Large MD, Serpe RT. The prevalence of body dysmorphic disorder in the United States adult population. CNS Spectr. 2008;13:316-322.

6. Buhlmann U, Glaesmer H, Mewes R, et al. Updates on the prevalence of body dysmorphic disorder: A populationbased survey. Psychiatry Res. 2010;178:171-175.

7. Crerand CE, Franklin ME, Sarwer DB. MOC-PS (SM) CME article: Patient safety. Body dysmorphic disorder and cosmetic surgery. Plast Reconstr Surg. 2008;122(Suppl):1-15.

8. Aouizerate B, Pujol H, Grabot D, et al. Body dysmorphic disorder in a sample of cosmetic surgery applicants. Eur Psychiatry 2003;18:365-368.

9. Dey JK, Ishii M, Phillis M, Byrne PJ, Boahene KD, Ishii LE. Body dysmorphic disorder in a facial plastic and reconstructive surgery clinic: Measuring prevalence, assessing comorbidities, and validating a feasible screening instrument. JAMA Facial Plast Surg. 2015;17:137-143.

10. De Jongh A, Aartman IH, Parvaneh H, Ilik M. Symptoms of body dysmorphic disorder among people presenting for cosmetic dental treatment: A comparative study of cosmetic dental patients and a general population sample. Community Dent Oral Epidemiol. 2009;37:350-356.

11. Phillips KA, Dufresne RG Jr, Wilkel CS, Vittorio CC. Rate of body dysmorphic disorder in dermatology patients. $\mathrm{J} \mathrm{Am}$ Acad Dermatol. 2000;42:436-441.

12. Sarwer DB. Awareness and identification of body dysmorphic disorder by aesthetic surgeons: Results of a survey of American Society for Aesthetic Plastic Surgery members. Aesthet Surg J. 2002;22:531-535.

13. Sarwer DB, Spitzer JC, Sobanko JF, Beer KR. Identification and management of mental health issues by dermatologic surgeons: A survey of American Society for Dermatologic Surgery members. Dermatol Surg. 2015;41:352-357.

14. Szepietowski JC, Salomon J, Pacan P, Hrehorów E, Zalewska A. Body dysmorphic disorder and dermatologists. JEur Acad Dermatol Venereol. 2008;22:795-799.

15. Veale D, De Haro L, Lambrou C. Cosmetic rhinoplasty in body dysmorphic disorder. BrJ Plast Surg. 2003;56:546-551.

16. Felix GA, de Brito MJ, Nahas FX, et al. Patients with mild to moderate body dysmorphic disorder may benefit from rhinoplasty. J Plast Reconstr Aesthet Surg. 2014;67:646-654.

17. Cook SA, Rosser R, James MI, Kaney S, Salmon P. Factors influencing surgeons' decisions in elective cosmetic surgery consultations. Med Decis Making 2007;27:311-320.

18. Mirivel JC. The physical examination in cosmetic surgery: Communication strategies to promote the desirability of surgery. Health Commun. 2008;23:153-170. 